Article

\title{
Phenolic Compounds from Merremia umbellata subsp. orientalis and Their Allelopathic Effects on Arabidopsis Seed Germination
}

\author{
Jian Yan ${ }^{1, \dagger}$, Hai-Hong Bi ${ }^{1, \dagger}$, Yong-Zhu Liu ${ }^{2}$, Mei Zhang ${ }^{1,3}$, Zhong-Yu Zhou ${ }^{1}$ and \\ Jian-Wen Tan ${ }^{1, *}$
}

1 Key Laboratory of Plant Resources Conservation and Sustainable Utilization, South China Botanical Garden, Chinese Academy of Sciences, Guangzhou 510650, China;

E-Mails: yanjian@scbg.ac.cn (J.Y.); bihaihong@scau.edu.cn (H.-H.B); amei1227@126.com (M.Z.); zhouzhongyu@scbg.ac.cn (Z.-Y.Z.)

2 National Engineering Research Center of Plant Space Breeding, Guangzhou 510642, China;

E-Mail: lively@scau.edu.cn

3 Graduate School of the Chinese Academy of Sciences, Beijing 100039, China

$\dagger$ These authors contributed equally to this work.

* Author to whom correspondence should be addressed; E-Mail: jwtan@scbg.ac.cn; Tel.: +86-20-37082054; Fax: +86-20-37082054.

Received: 15 September 2010; in revised form: 27 October 2010 / Accepted: 29 October 2010 / Published: 12 November 2010

\begin{abstract}
A bioassay-directed phytochemical study was carried out to investigate potential allelochemicals of the invasive plant Merremia umbellata subsp. orientalis (Hall. f.). Eight phenolic compounds, including a salicylic acid (SA)-derived new natural product, SA 2-O$\beta$-D-(3',6'-dicaffeoyl)-glucopyranoside (1), and seven known ones 2-8 were isolated and identified from two bioactive sub-fractions of the acetone extract of this plant. The structure of new compound $\mathbf{1}$ was established by spectral and chemical methods. The potential allelopathic effects of these compounds at 0.5 and $1.0 \mathrm{mM}$ concentrations on the germination of Arabidopsis seeds were tested. Results showed that $\mathbf{2}$ remarkably inhibited seed germination at concentrations as low as $0.5 \mathrm{mM}$. Compound 3 only moderately inhibited seed germination at $0.5 \mathrm{mM}$, but displayed strong inhibitory bioactivity at $1.0 \mathrm{mM}$ concentration. Compounds $\mathbf{4}$ and $\mathbf{5}$ showed only slight inhibitory bioactivity at $1.0 \mathrm{mM}$, while the other compounds showed no obvious inhibitory effects.
\end{abstract}


Keywords: Convolvulaceae; Merremia umbellata; phenolic compounds; Arabidopsis; Allelopathic effect; salicylic acid

\section{Introduction}

M. umbellata (Linn.) subsp. orientalis (Hall. f.) belonging to the family Convolvulaceae is a typical liana plant found in many tropical and subtropical Asian countries like India, Vietnam and Laos, and this plant is also recorded in Australia, eastern Africa and some Pacific Ocean islands [1]. In China, this plant was previously mainly distributed in Guangxi, Yunnan and Hainan provinces, while recently it was also found in some parts of Guangdong Province as an introduced harmful invasive plant [2]. Just like some other well-known invasive plants such as Centaurea maculosa in North America [3] and Eupatorium adenophorum in Asia [4], it could be speculated that the generation of potential allelochemicals would possibly be an important factor for this plant to achieve its invasive success. However, though diverse resin glycosides [5-10], phenolic compounds [11-14], furanosesquiterpenoids [15], pyrrolidine and tropane alkaloids [16] have been identified from some Merremia genus plants, no particular chemical constituents of this plant or their potential allelopathic activities have been reported so far. As one part of our study on invasion mechanisms of invasive plants in China, we carried out a bioassay-directed phytochemical investigation on potential allelochemicals of $M$. umbellata subsp. orientalis, which led to the isolation and identification of eight phenolic compounds, including a new salicylic acid (SA)-derived natural product, SA 2-O- $\beta$-D-(3',6'-dicaffeoyl)-glucopyranoside (1), and seven known ones (2-8, see Figure 1) from two bioactive sub-fractions (Fr.2 and Fr.5) of an acetone extract of this plant.

Figure 1. Phenolic compounds isolated from M. umbellata subsp. orientalis.
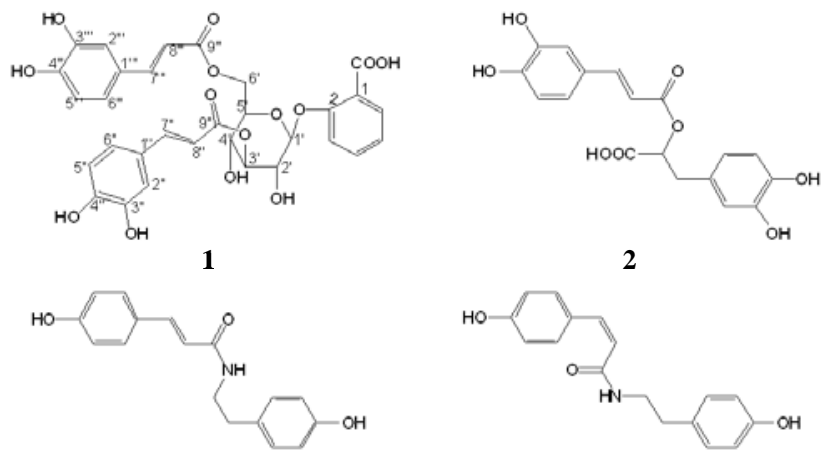

2

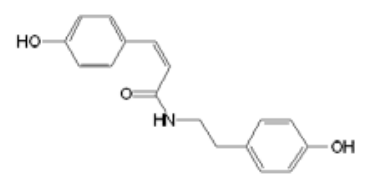

4

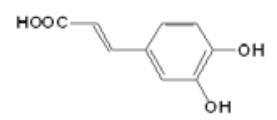

5

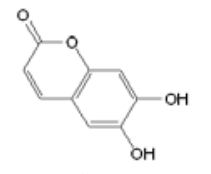

6
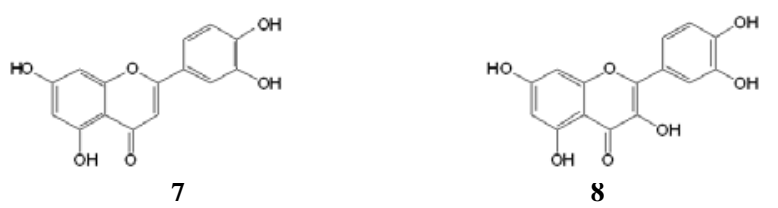
Here we report the isolation and structure elucidation of these compounds and their potential allelopathic effects tested on the germination of Arabidopsis seeds.

\section{Results and Discussion}

The acetone extract of whole plant fresh tissues of $M$. umbellata subsp. orientalis was partitioned with EtOAc and $10 \%$ ethanol in $\mathrm{H}_{2} \mathrm{O}$, and the obtained EtOAc extract was subsequently subjected to silica gel column chromatography, eluted with a $\mathrm{CHCl}_{3} / \mathrm{MeOH}$ system, to afford seven sub-fractions (Fr.1-7). The allelopathic effects of the seven sub-fractions on the germination of Arabidopsis seeds were tested by using a literature method [4], as described in the Experimental, and the results showed that sub-fractions Fr.2 and Fr.5 were capable of remarkably inhibiting the germination of Arabidopsis seeds at concentrations as low as $0.5 \mathrm{mg} / \mathrm{mL}$ (Figure 2). This suggested that potential allelochemicals of the plant in the acetone extract would have mainly been partitioned and concentrated into Fr.2 and Fr.5, therefore these sub-fractions were further phytochemically analyzed in the search for potential allelochemicals, which eventually led to the isolation of compounds 1, 2 and 3 from Fr.5 and 4, 5, 6, 7 and 8 from Fr.2.

Figure 2. Arabidopsis seed germination rates recorded after three days in Hoagland medium containing sub-fractions (Fr.1-Fr.7) of the acetone extract of the plant fresh tissues at the indicated concentrations or nothing (A: bioactive assay for all seven sub-fractions at 3.0 and $5.0 \mathrm{mg} / \mathrm{mL}$ concentrations; B: further bioactive assay for Fr.2, Fr.5 and Fr.6 at 0.5 and $1.0 \mathrm{mg} / \mathrm{mL}$ concentrations; control: filter paper treated with $3 \mathrm{~mL}$ of pure acetone). Values are means \pm s.d. from three independent experiments (30 seeds per treatments). Seeds germination rate $=($ number of germinated seeds $/ 30) \times 100 \%$.

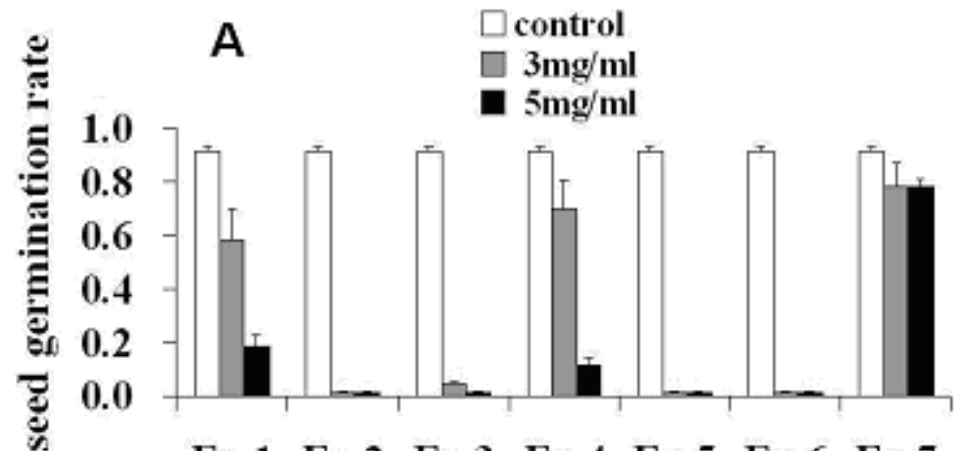

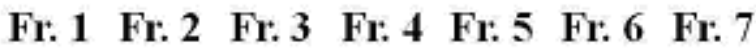
Sub-Fractions

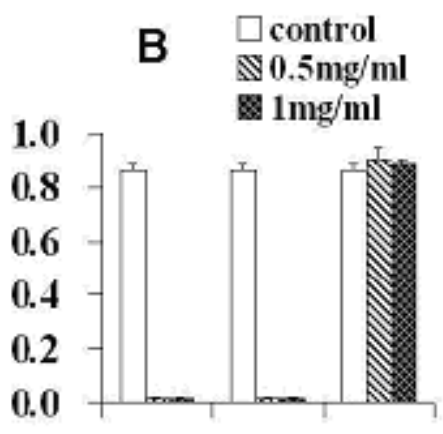

Fr:2 $\quad$ Fr.5 Fr.6

Sub-Fractions

Compound 1 was obtained as a white, amorphous powder. Its HR-ESI-MS exhibited a molecular ion peak at $\mathrm{m} / \mathrm{z} 623.1422$ [M-H] $]^{-}$corresponding to a molecular formula of $\mathrm{C}_{31} \mathrm{H}_{28} \mathrm{O}_{14}$ (calcd. 623.1400). IR absorptions at $3,374 \mathrm{~cm}^{-1}$ (br.) and 1,695 $\mathrm{cm}^{-1}$ (br.), implied the existence of hydroxyl and conjugated carbonyl groups. In its ${ }^{13} \mathrm{C}$-NMR and DEPT spectra, the thirty-one carbon signals of the molecule $\left(11 \times \mathrm{C}, 19 \times \mathrm{CH}, 1 \times \mathrm{CH}_{2}\right.$, three carbonyl group C-atoms and twenty-two $s p^{2} \mathrm{C}$-atoms) could all be assigned (see Table 1). The presence of a D-glucopyranose moiety in the molecule was suggested by the presence of carbon signals at $\delta_{\mathrm{C}} 103.9(\mathrm{CH}), 73.3(\mathrm{CH}), 78.1(\mathrm{CH}), 70.0(\mathrm{CH}), 75.8(\mathrm{CH})$ and 
$64.3\left(\mathrm{CH}_{2}\right)$, confirm by the presence of signals at $\delta_{\mathrm{H}} 5.04\left(1 \mathrm{H}, \mathrm{H}-1^{\prime}\right), 3.78\left(1 \mathrm{H}, \mathrm{H}-2^{\prime}\right), 5.19\left(1 \mathrm{H}, \mathrm{H}-3^{\prime}\right)$, 3.68 (1H, H-4'), 3.87 (1H, H-5'), 4.56 (1H, Ha-6') and 4.44 (1H, Hb-6') in its ${ }^{1} \mathrm{H}-\mathrm{NMR}$ spectrum.

Table 1. ${ }^{1} \mathrm{H}$ - and ${ }^{13} \mathrm{C}-\mathrm{NMR}$ spectral data of compound $\mathbf{1}$.

\begin{tabular}{llllll}
\hline No. & $\boldsymbol{\delta}(\mathbf{C})$ & $\boldsymbol{\delta}(\mathbf{H})$ & No. & $\boldsymbol{\delta}(\mathbf{C})$ & $\boldsymbol{\delta} \mathbf{( H )}$ \\
\hline 1 & 123.0 & & $1^{\prime \prime}$ & 127.9 & \\
2 & 158.4 & & $2^{\prime \prime}$ & 115.3 & $7.07(1 \mathrm{H}, \mathrm{d}, 2.4)$ \\
3 & 119.2 & $7.81(1 \mathrm{H}, \mathrm{dd}, 7.8,1.2)$ & $3^{\prime \prime}$ & 146.9 & \\
4 & 134.9 & $7.42(1 \mathrm{H}, \mathrm{dt}, 7.8,1.2)$ & $4^{\prime \prime}$ & 149.7 & \\
5 & 124.0 & $7.10(1 \mathrm{H}, \mathrm{dt}, 7.8,1.2)$ & $5^{\prime \prime}$ & 116.6 & $6.80(1 \mathrm{H}, \mathrm{d}, 8.4)$ \\
6 & 132.5 & $7.34(1 \mathrm{H}, \mathrm{dd}, 7.8,1.2)$ & $6^{\prime \prime}$ & 123.0 & $6.79(1 \mathrm{H}, \mathrm{dd}, 8.4,2.4)$ \\
7 & 169.7 & & $7^{\prime \prime}$ & 147.3 & $7.62(1 \mathrm{H}, \mathrm{d}, 16.2)$ \\
$1^{\prime}$ & 103.9 & $5.04(1 \mathrm{H}, \mathrm{d}, 7.8)$ & $8^{\prime \prime}$ & 115.2 & $6.36(1 \mathrm{H}, \mathrm{d}, 16.2)$ \\
$2^{\prime}$ & 73.3 & $3.78(1 \mathrm{H}, \mathrm{dd}, 9.6,7.8)$ & $9^{\prime \prime}$ & 168.9 & \\
$3^{\prime}$ & 78.1 & $5.19(1 \mathrm{H}, \mathrm{dd}, 9.6,9.0)$ & $1^{\prime \prime \prime}$ & 127.7 & \\
$4 '$ & 70.0 & $3.68(1 \mathrm{H}, \mathrm{dd}, 9.6,9.0)$ & $2^{\prime \prime \prime}$ & 115.2 & $7.06(1 \mathrm{H}, \mathrm{d}, 1.8)$ \\
$5^{\prime}$ & 75.8 & $3.87(1 \mathrm{H}, \mathrm{m})$ & $3^{\prime \prime \prime}$ & 146.8 & \\
6'a & 64.3 & $4.56(1 \mathrm{H}, \mathrm{dd}, 12.0,1.8)$ & $4^{\prime \prime \prime}$ & 149.6 & \\
6'b & & $4.44(1 \mathrm{H}, \mathrm{dd}, 12.0,6.6)$ & $5^{\prime \prime \prime}$ & 116.5 & $6.78(1 \mathrm{H}, \mathrm{d}, 8.4)$ \\
& & & $6^{\prime \prime \prime}$ & 122.9 & $6.69(1 \mathrm{H}, \mathrm{dd}, 8.4,1.8)$ \\
& & & $7^{\prime \prime \prime}$ & 147.2 & $7.59(1 \mathrm{H}, \mathrm{d}, 15.6)$ \\
& & & $8^{\prime \prime \prime}$ & 114.9 & $6.31(1 \mathrm{H}, \mathrm{d}, 15.6)$ \\
\hline
\end{tabular}

Data were measured at $600 \mathrm{MHz}$ for ${ }^{1} \mathrm{H}$ and $150 \mathrm{MHz}$ for ${ }^{13} \mathrm{C}$ in $\mathrm{CD}_{3} \mathrm{OD}, \delta$ in ppm and $J$ in $\mathrm{Hz}$.

Coupled with ${ }^{1} \mathrm{H}-{ }^{1} \mathrm{H}$ COSY and HSQC spectral analysis, aromatic proton signals at $\delta_{\mathrm{H}} 7.81(1 \mathrm{H}$, $\mathrm{H}-3), 7.42(1 \mathrm{H}, \mathrm{H}-4), 7.10(1 \mathrm{H}, \mathrm{H}-5)$ and $7.34(1 \mathrm{H}, \mathrm{H}-6)$ belonging to a salicylic acid moiety, and aromatic and olefinic proton signals of two caffeic acid moieties at $\delta_{\mathrm{H}} 7.07(1 \mathrm{H}, \mathrm{H}-2 "), 6.80(1 \mathrm{H}, \mathrm{H}-5 ")$, $6.79(1 \mathrm{H}, \mathrm{H}-6 "), 7.06$ (1H, H-2"'), 6.78 (1H, H-5"'), 6.69 (1H, H-6"'), and $\delta_{\mathrm{H}} 7.62(1 \mathrm{H}, \mathrm{H}-7 "), 6.36(1 \mathrm{H}$, H-8"), 7.59 (1H, H-7'"), 6.31 (1H, H-8'"), were all observed (see Figure 3). The presented coupling constants between H-7"(7"') and H-8"'(8'") olefeinic protons $\left(J_{7^{\prime \prime}, 8^{\prime \prime}}=16.2 \mathrm{~Hz}, J_{7^{\prime \prime \prime}, 8^{\prime \prime \prime}}=15.6 \mathrm{~Hz}\right)$ suggested that the two double bonds in the two caffeic acid moieties, respectively, were all $E$ geometry. In the HMBC spectrum, the observation of ${ }^{1} \mathrm{H}-{ }^{13} \mathrm{C}$ long-range correlations of $\mathrm{H}-7$ "(7"') with C-2"(2"') and C-6"(6"'), H-8"(8"') with C-1"(1"') and C-9"(9"') indicated the direct linkage of C-1"(1"') with C7"(7"'), and C-8"(8"') with C-9"(9"'). The bonding of the 7-COOH group with $\mathrm{C}-1$ was supported by the observation of a significant HMBC correlation of H-6 ( $\left.\delta_{\mathrm{H}} 7.34\right)$ with C-7 $\left(\delta_{\mathrm{C}} 169.7\right)$. The 2-O- $\beta$-Dglucopyranoside linkage was assigned based on the HMBC correlation of $\mathrm{H}-1$ ' with $\mathrm{C}-2$ and the coupling constant of the anomeric proton $\left(\mathrm{H}-1{ }^{\prime}, \delta_{\mathrm{H}} 5.04, d, J=7.8 \mathrm{~Hz}\right)$ shown in its ${ }^{1} \mathrm{H}-\mathrm{NMR}$ spectrum. The ester bond linkage of two caffeic acid units with the sugar moiety at C-3' and C-6' positions were revealed by the observation of significant HMBC correlations of H-3' with C-9" and H-6' with C-9'". Those spectral data led us to establish the structure of $\mathbf{1}$ as SA 2-O- $\beta$-D-(3',6'-dicaffeoyl)-glucopyranoside. 
Figure 3. Key HMBC and COSY correlations of compound 1.

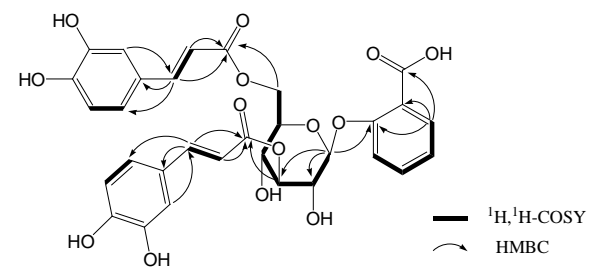

In order further to confirm the configuration of the glucose moiety in the new structure, the permethylated product $\mathbf{1}(\mathbf{X})$ prepared from the sugar unit released by hydrolyzation from $\mathbf{1}$ was compared by GC-MS analysis with permethylated products $\mathbf{D}(+)$ and $\mathbf{L ( - )}$ prepared from authentic Dand L-glucose, respectively. Results showed that $\mathbf{1 ( X )}$ (with retention time of $3.39 \mathrm{~min}$ ) was consistent with $\mathbf{D}(+)$ (with retention time of $3.38 \mathrm{~min}$ ), but obviously different from $\mathbf{L}(-)$ (with a retention time of $3.67 \mathrm{~min}$ ), indicating that the sugar moiety in $\mathbf{1}$ was a D-glucose unit, which further confirmed our deduction about the structure of $\mathbf{1}$ as SA 2-O- $\beta$-D-(3',6'-dicaffeoyl)-glucopyranoside.

The seven known phenolic compounds were identified as rosmarinic acid (2) [17,18], paprazine (3) [19], $N$-P-cis-coumaroyltyramine (4) [20], caffeic acid (5) [18,21], esculetin (6) [22], quercetin (7) [22,23], and luteolin (8) [24], respectively, by comparison of their spectral data with those in the literature. All of these compounds were isolated from $M$. umbellata subsp. orientalis for the first time.

Interference of invasive plants with the growth and establishment of native plants via allelopathy has been indicated in a number of recent studies as one of the most important factors for invasive plants to achieve their invasion success. So far, structurally diverse allelochemicals have already been discovered in several invasive species, such as catechin from Centaurea maculosa [3] and various sesquiterpenoids from Eupatorium adenophorum [4], etc. The allelopathic effects of the phenolic compounds obtained in this study were tested at $0.5 \mathrm{mM}$ and $1.0 \mathrm{mM}$ concentrations, respectively, on the germination of Arabidopsis seeds, using a literature method [4] as described in the Experimental section, in which the seeds' germination rates three days post-innoculation were recorded. Results showed that $\mathbf{2}$ remarkably inhibited Arabidopsis seed germination at both concentrations. Compound 3 significantly inhibited seed germination at $1.0 \mathrm{mM}$, but showed only moderate bioactivity at $0.5 \mathrm{mM}$ concentration. Compounds $\mathbf{4}$ and $\mathbf{5}$ only slightly inhibited the seed germination at $1.0 \mathrm{mM}$ concentration, and no inhibitory effects were exhibited by the other compounds at concentrations tested (Figure 4).

Phenolic compounds functioning as allelochemicals have already been addressed in several different invasive plant species $[3,25,26]$, among which catechin is so far the most comprehensively investigated one in the literature [27]. Our study indicated that several phenolic compounds in $M$. umbellata subsp. orientalis were also biologically active and they could also be potential allelochemicals. Since more than one compound with allelopathic potential was discovered in this plant, it could be speculated that synergistic effects of those potential allelochemicals could exist for this plant to exert its potential allelopathic effects. Compounds $\mathbf{7}$ and $\mathbf{8}$ are two typical flavonoids, whose structures are close to that of the highly bioactive compound catechin, but no obvious allelopathic effects were exhibited by these two compounds in our experiments, which suggests that the $\mathrm{C}-2, \mathrm{C}-3$ chairal centres and the $\beta-\mathrm{OH}$ group at $\mathrm{C}-3$ of catechin might be necessary for the phytotoxicity of flavonoids of this type. 
Figure 4. Arabidopsis seed germination rates recorded after three days in Hoagland medium containing one of the isolated compounds 1-8 at the indicated concentrations or nothing (control: filter paper treated with $3 \mathrm{~mL}$ of pure acetone). Bars indicate maximal deviations from mean values derived from three independent measurements. Seeds germination rate $=$ (number of germinated seeds/30) $\times 100 \%$.

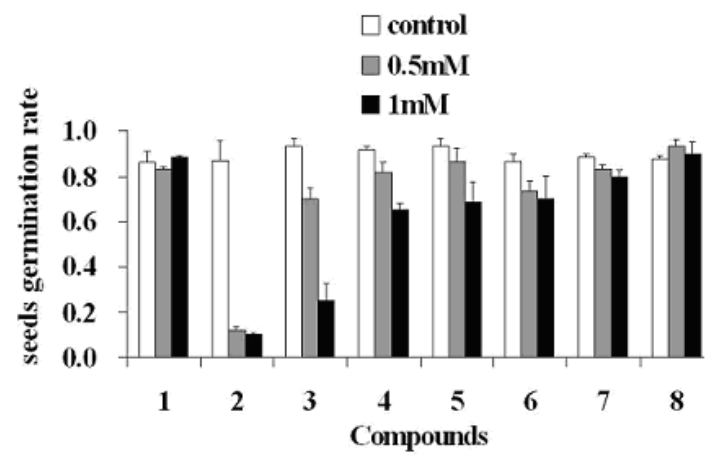

The new compound $\mathbf{1}$ showed no biological activity in our bioactivity assay, which in itself is interesting since $\mathbf{1}$ is a salicylic acid (SA)-containing molecule and according to the literature, SA is an important signaling molecule that mediates plant defense against microbial pathogens $[28,29]$. Since SAG has been confirmed to be an important slow-release storage form of SA for regulation of SAelicited defense reactions [30], it is reasonable to predict that $\mathbf{1}$ might be a new storage form of SA in higher plants, or at least in this plant, to regulate SA-elicited defense responses.

\section{Experimental}

\subsection{General}

Uncorrected melting points (m.p.) were obtained on a Sichuan micro-melting-point apparatus (XRC-1). Optical rotations were measured on a Horiba SEPA-300 spectropolarimeter. IR spectra ( $\mathrm{KBr})$ were recorded on a Bruker Tensor 27 spectrophotometer in $\mathrm{cm}^{-1}$. 1D and $2 \mathrm{D}{ }^{1} \mathrm{H}$ - and ${ }^{13} \mathrm{C}-\mathrm{NMR}$ spectra were recorded in $\mathrm{CD}_{3} \mathrm{OD}$ on a Bruker AVANCE-600 instrument with TMS as an internal standard. ESIMS and HRESIMS were recorded on a VG-Autospec-3000 spectrometer. For column chromatography (CC), silica gel (200-300 mesh, Qingdao Marine Chemical Inc., Peoples Republic of China), Lichroprep RP-18 gel (40-63 um, Merck, Darmstadt, Germany) and Sephadex LH-20 (Pharmacia Fine Chemical Co. Ltd.) were used. Fractions were monitored by TLC, and spots were visualized by heating the silica gel plates sprayed with $10 \% \mathrm{H}_{2} \mathrm{SO}_{4}$ in ethanol.

\subsection{Plant Material}

Whole plant fresh M. umbellata subsp. orientalis (Hall. f.) materials were collected at Longdong forest park in Guangzhou, Guangdong Province, Peoples Republic of China, in February 2009, and identified by Prof. Fuwu Xing, South China Botanical Garden, Chinese Academy of Sciences (CAS). The voucher specimen (NO: 20090222) was deposited at the Laboratory of Phytochemistry of the South China Botanical Garden, CAS. 


\subsection{Extraction and Isolation}

The freshly collected M. umbellata subsp. orientalis material $(7.7 \mathrm{~kg}$ ) was cut into pieces and exhaustively extracted for three times with $80 \%$ acetone $\left(\right.$ in $\left.\mathrm{H}_{2} \mathrm{O}\right)$ at room temperature $(3 \times 30 \mathrm{~L})$. The acetone extract was then evaporated to dryness under reduced pressure to remove most of the acetone and re-suspended in $10 \%$ methanol in $\mathrm{H}_{2} \mathrm{O}(2,500 \mathrm{~mL})$. The re-suspended solution was then extracted with EtOAc $(2,000 \mathrm{~mL} \times 3)$ and the EtOAc extract was subsequently evaporated to dryness to give 48 g of oily EtOAc extract. This EtOAc extract (48 g) was further subjected to column chromatography over silica gel column (200-300 mesh, $1.2 \mathrm{~kg}$ ) eluted with a gradient solvent system of $\mathrm{CHCl}_{3} / \mathrm{MeOH}$ (0-100\% methanol) to afford seven sub-fractions Fr.1-7. As a result of the bioassay-guided analysis, Fr.2 and Fr.5 were mainly investigated. Fr.2 was fractionated into five sub-fractions by CC. Fr. 2.2 (5.8 g) was repeatedly subjected to CC (silica gel, $\mathrm{CHCl}_{3} / \mathrm{MeOH} 25: 1$ to $10: 1$ ) to give compounds 5 (1 g, yield:17.24\%), 6 (23 mg, 0.40\%), 7 (20 mg, 0.34\%) and 8 (11 mg, 0.19\%), and further purified by prep. HPLC to yield compound 4 (12 mg, 0.21\%). Fr.5 (2.1 g) was also repeatedly subjected to CC eluting with $\mathrm{CHCl}_{3} / \mathrm{CH}_{3} \mathrm{OH}$ (40:1) to afford compounds 2 (16 mg, 0.76\%), 3 (60 mg, 2.86\%), and further purified by Sephadex LH-20 column eluting with $\mathrm{MeOH}$ to give a white powder of the new compound 1 (10 mg, 0.48\%). SA 2-O- $\beta$-D-(3',6'-dicaffeoyl)-glucopyranoside (1). white powder; m.p.: 168-170 ${ }^{\circ} \mathrm{C} ;[\alpha]^{20}{ }_{\mathrm{D}}:+85.5$ (c 0.08, $\left.\mathrm{CH}_{3} \mathrm{OH}\right)$; UV $\lambda_{\max }\left(\mathrm{CH}_{3} \mathrm{OH}\right) \mathrm{nm}(\log \varepsilon): 217$ (4.39), 329 (4.39); IR $(\mathrm{KBr}) v_{\max } 3374,1695,1602,1517,1488,1450,1355,1278,1160,1112 \mathrm{~cm}^{-1}$; ${ }^{1} \mathrm{H}-\mathrm{NMR}\left(\mathrm{CD}_{3} \mathrm{OD}\right)$ data, see Table 1; ${ }^{13} \mathrm{C}-\mathrm{NMR}\left(\mathrm{CD}_{3} \mathrm{OD}\right)$ data, see Table 2; ESI-MS (negative) $\mathrm{m} / \mathrm{z}$ 623, HR-ESI-MS (negative): $623.1422\left([\mathrm{M}-\mathrm{H}]^{-}\right.$, calcd. for $\left.\mathrm{C}_{31} \mathrm{H}_{27} \mathrm{O}_{14}{ }^{-}, 623.1400\right)$.

\subsection{Hydrolysis, Sugar Permethylation and GC-MS Analysis}

Compound 1 (2 mg) was refluxed with a mixture of $\mathrm{MeOH}(1 \mathrm{~mL})$ and $5 \% \mathrm{H}_{2} \mathrm{SO}_{4}(1 \mathrm{~mL})$ at $90{ }^{\circ} \mathrm{C}$ for 2 h. The reaction mixture was diluted with $\mathrm{H}_{2} \mathrm{O}(2 \mathrm{~mL})$ and extracted with EtOAc $(1.5 \mathrm{~mL})$. The aqueous layer was neutralized with $10 \% \mathrm{NaHCO}_{3}(1.1 \mathrm{~mL})$ and concentrated to give a residue, in which the sugar unit released from 1 was contained. The residue was further dissolved in anhydrous DMSO (1 mL), KOH (1 mg) and $\mathrm{CH}_{3} \mathrm{I}(1 \mathrm{~mL})$ added for permethylation, and the mixture was allowed to react at room temperature for $1 \mathrm{~h}$. Then the reaction was stopped by addition of $\mathrm{H}_{2} \mathrm{O}(2 \mathrm{~mL})$ and the reaction mixture was then extracted with $\mathrm{CHCl}_{3}(3 \times 1.5 \mathrm{~mL})$. The combined organic layers were washed with $\mathrm{H}_{2} \mathrm{O}(3 \mathrm{~mL})$, and evaporated to afford the permethylated sugar product $\mathbf{1}(\mathbf{X})$. The permethylated products $\mathbf{D}(+)$ and $\mathbf{L}(-)$ of authentic sugars D-glucose and L-glucose (Sigma), respectively, were prepared with the same method as for $\mathbf{1}(\mathrm{X})$. GC-MS analyses was carried out to compare $\mathbf{1}(\mathbf{X})$ with $\mathbf{D}(+)$ and $\mathbf{L ( - )}$ by using a GCMS-QP2010 PLUS instrument, RXI ${ }^{\mathrm{R}}-5 \mathrm{~ms}$ capillary column (30m, $0.25 \mathrm{~mm}$ ID), Helium at constant rate of $40 \mathrm{~cm} / \mathrm{s}, 5 \mathrm{uL}$ injection valume, injector temperature at $290{ }^{\circ} \mathrm{C}$, temperature program as $50{ }^{\circ} \mathrm{C}$ for $3 \mathrm{~min}$, then $15{ }^{\circ} \mathrm{C} / \mathrm{min}$ to $180{ }^{\circ} \mathrm{C}$, hold for $10 \mathrm{~min}$, then $15{ }^{\circ} \mathrm{C} / \mathrm{min}$ to $280{ }^{\circ} \mathrm{C}$, hold for $8 \mathrm{~min}$, then $40{ }^{\circ} \mathrm{C} / \mathrm{min}$ to $300{ }^{\circ} \mathrm{C}$, hold for $20 \mathrm{~min}$. Electron ionization mode was used at $70 \mathrm{eV}$. The mass range was 100-900 amu. The temperature of the ion source was $220^{\circ} \mathrm{C}$. The retention times detected were $3.39 \mathrm{~min}$ for $\mathbf{1}(\mathbf{X}), 3.38 \mathrm{~min}$ for $\mathbf{D}(+)$ and 3.67 min for $\mathbf{L}(-)$. The consistency of the retention time of $\mathbf{1}(\mathbf{X})$ with that of $\mathbf{D}(+)$ confirmed our deduction that the sugar moiety in $\mathbf{1}$ had a D-configuration. 


\subsection{Seed Germination Bioassay}

Arabidopsis thaliana was washed with ethanol $(70 \% \mathrm{v} / \mathrm{v})$ for $2 \mathrm{~min}$ and surface sterilized using sodium hypochlorite $(0.5 \% \mathrm{v} / \mathrm{v})$ for $2 \mathrm{~min}$, followed by three washes with sterile distilled water. After surface sterilization, seeds were stored in a refrigerator at $4{ }^{\circ} \mathrm{C}$ for three days before use. Three layers of filter paper were put in 6-cm-diameter glass Petri dishes, and the filter papers were impregnated with the compounds dissolved in methanol $(2 \mathrm{~mL})$. Concentrations of sub-fractions and compounds were as indicated in Figures 2 and 4. To avoid toxic effects of the organic solvent, filter paper treated with acetone solution was placed in a fume cupboard for $1 \mathrm{~h}$ to allow complete solvent evaporation [31]. Subsequently, Hoagland solution ( $1 \mathrm{~mL}$ ) was added to each piece of filter paper in each Petri dish [32]. Thirty Arabidopsis seeds were evenly placed on the moist filter paper in each Petri dish. Two controls (filter paper treated with $2 \mathrm{~mL}$ of methanol and filter paper without any treatment) were used. Each treatment had three duplicates. Seeds were allowed to germinate under $12 \mathrm{~h}$ light and $12 \mathrm{~h}$ dark at $25{ }^{\circ} \mathrm{C}$ (day) and $20{ }^{\circ} \mathrm{C}$ (night). The light intensity in the growth chamber was $100 \mu \mathrm{mol} \mathrm{m} \mathrm{m}^{-2}$. The number of germinated seeds was recorded after treatment for three days, at which time most seeds $(\geq 80 \%)$ in the control Petri dishes were germinated.

\section{Conclusions}

Eight phenolic compounds, including a new salicylic acid-derived natural product SA 2-O- $\beta$-D(3',6'-dicaffeoyl)-glucopyranoside, and seven known ones were isolated from the invasive plant $M$. umbellata subsp. orientalis (Hall. f.), and some of them showed inhibitory bioactivities on the germination of Arabidopsis seeds. Our study provides new data to support the idea that phenolic compounds could play a role as allelochemicals in helping invasive plants achieve their invasion success. Our research does not exclude the possibility that some other types of allelochemicals would also exist in this plant, and this possibility could be gradually clarified with the functional identification of more chemical constituents of this plant in the future.

\section{Acknowledgements}

The authors are grateful for the financial support from the Chinese Academy of Sciences (KSCX2YW-N-0804, Talent Project of SCBG 200733, 200747), Key Laboratory of Plant Resources Conservation and Sustainable Utilization, South China Botanical Garden, CAS (200920) and the National Natural Science Foundation of China (30870248, 30900125 to J.Y.).

\section{References and Notes}

1. Wu, D.L. Flora of Guangdong; Guangdong Science and Technology Press: Guangzhou, China, 2000; Volume 4, p. 345.

2. Chen, B.H.; Wang, R.J.; Huang, X.L.; Zhou, L.X. Merremia boisiana - a newly recorded species from Guangdong, China. J. Trop. Subtrop. Bot. 2005, 13, 76-77.

3. Fitter, A. Making Allelopathy Respectable. Science 2003, 301, 1377-1380. 
4. Zhao, X.; Zheng, G.W.; Niu, X.M.; Li, W.Q.; Wang, F.S.; Li, S.H. Terpenes from Eupatorium adenophorum and their allelopathic effects on Arabidopsis seeds germination. J. Agr. Food Chem. 2009, 57, 478-482.

5. Kitagawa, I.; Shibuya, H.; Yokokawa, Y.; Baek, N.I.; Ohashi, K.; Yoshikawa, M.; Nitta, A.; Wariadinata, H. Structures of merremosides B and D, new antiserotonic resin-glycosides from the tube of Merremia mammosa, an Indonesian folk medicine. Chem. Pharm. Bull. 1988, 36, 1618-1622.

6. Kitagawa, I.; Baek, N.I.; Ohashi, K.; Sakagami, M.; Yokokawa, Y.; Shibuya, H. Mammosides B and H1, new ionophoric resin-glycosides from the tube of Merremia mammosa, an Indonesian folk medicine. Chem. Pharm. Bull. 1989, 37, 1131-1133.

7. Kitagawa, I.; Baek, N.I.; Kawashima, K.; Yokokawa, Y.; Yoshikawa, M.; Ohashi, K.; Shibuya, H. Indonesian medicinal plants. XV. chemical structures of five new resin-glycosides, merremosides a, b, c, d, and e, from the tuber of Merremia mammosa (Convolvulaceae). Chem. Pharm. Bull. 1996, 44, 1680-1692.

8. Kitagawa, I.; Baek, N.I.; Yokokawa, Y.; Yoshikawa, M.; Ohashi, K.; Shibuya, H. Indonesian medicinal plants. XVI. chemical structures of four new resin-glycosides, merremosides $f, g, h_{1}$, and $\mathrm{h}_{2}$, from the tuber of Merremia mammosa (Convolvulaceae). Chem. Pharm. Bull. 1996, 44, 1693-1699.

9. Noda, N.; Tsuji, K.; Miyahara, K.; Yang, C.R. Resin glycosides. XXI. tuguajalapins I-X, the resin glycosides having long-chain fatty acid groups from the root of Merremia hungaiensis. Chem. Pharm. Bull. 1994, 42, 2011-2016.

10 Noda, N.; Tsuji, K.; Kawasaki, T.; Miyahara, K.; Hanazono, H.; Yang, C.R. A novel resin glycoside, merremin (tuguajalapin X dimer), from Merremia hungaiensis. Chem. Pharm. Bull. 1995, 43, 1061-1062.

11. Krishnappan, A.L.; Seetharaman, T.R. Flavonoids of Merremia tridentate. Fitoterapia 1992, 63, 190.

12. Garcia-Argaez, A.N.; Perez-Amador, M.C.; Aguirre-Hernandez, E.; Martinez-Vazquez, M. Two new caffeate esters from roots of Merremia tuberosa and M. dissecta. Planta Med. 1999, 65, 678-679.

13. Khan, A.M.; Rathor, O.S. Phenolic acids of Merremia emarginata Hallier F. Himalayan Chem. Pharm. Bull. 1985, 2, 12.

14. Gao, G.C.; Wu, P.; Cao, H.L.; Lin, L.D.; Wei, X.Y. Phenolic compounds from Merremia boisiana (Convolvulaceae). J. Trop. Subtrop. Bot. 2006, 14, 233-237.

15. Jenett-Siems, K.; Siems, K.; Witte, L.; Eich, E. Merrekentrones AD, ipomeamarone-like furanosesquiterpenes from Merremia kentrocaulos. J. Nat. Prod. 2001, 64, 1471-1473.

16. Jenett-Siems, K.; Weigl, R.; Böhm, A.; Mann, P.; Tofern-Reblin, B.; Ott, S.C.; Ghomian, A.; Kaloga, M.; Siems, K.; Witte, L.; Hilker, M.; Müller, F.; Eich, E. Chemotaxonomy of the pantropical genus Merremia (Convolvulaceae) based on the distribution of tropane alkaloids. Phytochemistry 2005, 66, 1448-1464.

17. Kelley, C.J.; Harruff, R.C.; Carmack, M. Polyphenolic acids of Lithospermum ruderale. II. Carbon-13 nuclear magnetic resonance of lithospermic and rosmarinic acids. J. Org. Chem. 1976, 41, 449-454. 
18. Kelley, C.J.; Mahajan, J.R.; Brooks, L.C.; Neubert, L.A.; Breneman, W.R.; Carmack, M. Polyphenolic acids of Lithospermum ruderale (Boraginaceae). I. Isolation and structure determination of lithospermic acid. J. Org. Chem. 1975, 40, 1804-1805.

19. Rahman, A.U.; Bhatti, M.K.; Akhtar, F.; Choudhary, M.I. Alkaloids of Fumaria indica. Phytochemistry 1992, 31, 2869-2872.

20. Wu, T.S.; Ou, L.F.; Teng, C.M. Aristolochic acids, aristolactam alkaloids and amides from Aristolochia kankauensis. Phytochemistry 1994, 36, 1063-1068.

21. Schnarr, G.W.; Vyas, D.M.; Szarek, W.A. Carbon-13 nuclear magnetic resonance spectra of acyclic carbohydrate derivatives : alditols, 1,2-bis(phenylhydrazones), and dithioacetals. $J$. Chem. Soc. Perkin Trans. 1979, 1, 496-503.

22. Zhang, W.X.; Bao, W.F. Studies on the chemical constituents of Xanthoceras sorbifolia Bunge. Acta Pharm. Sinica 2000, 35, 124-127.

23. Shen, C.C.; Changa, Y.S.; Hott, L.K. Nuclear magnetic resonance studies of 5,7dihydroxyflavonoids. Phytochemistry 1993, 34, 843-845.

24 Youssef, D.; Frahm, A.W. Constituents of the Egyptian Centaurea scoparia; III. Phenolic constituents of the aerial parts. Planta Med. 1995, 61, 570-573.

25. Kalinova, J.; Vrchotova, N.; Triska, J. Exudation of allelopathic substances in buckwheat (Fagopyrum esculentum Moench). J. Agr. Food Chem. 2007, 55, 6453-6459.

26. Reigosa, M.J.; Malvido-Pazos, E. Phytotoxic effects of 21 plant secondary metabolites on Arabidopsis thaliana germination and root growth. J. Chem. Ecol. 2007, 33, 1456-1466.

27. Cipollini, D.; Stevenson, R.; Enright, S.; Eyles, A.; Bonello, P. Phenolic metabolites in leaves of the invasive shrub, Lonicera maackii, and their potential phytotoxicand anti-herbivore effects. $J$. Chem. Ecol. 2008, 34, 144-152.

28. Durrant, W.E.; Dong, X. Systemic acquired resistance. Annu. Rev. Phytopathol. 2004, 42, 185-209.

29. Loake, G.; Grant, M. Salicylic acid in plant defence-the players and protagonists. Curr. Opin. Plant Biol. 2007, 10, 466-472.

30. Lee, H.I.; Raskin, I. Glucosylation of salicylic acid in Nicotiana tabacum Cv. Xanthi-nc. Phytopathol. 1998, 88, 692-697.

31. Bertin, C.; Weston, L.A.; Huang, T.; Jander, G.; Owens, T.; Meinwald, J.; Schroeder, F.C. Grass roots chemistry: metatyrosine, an herbicidal nonprotein amino acid. Proc. Natl. Acad. Sci. USA 2007, 104, 16964-16969.

32. Diana, H.; Dudy, B.Z. An improved, simple, hydroponic method for growing Arabidopsis thaliana. Plant Mol. Biol. Rep. 2003, 21, 59-63.

Sample Availability: Samples of the compounds are available from the authors.

(C) 2010 by the authors; licensee MDPI, Basel, Switzerland. This article is an open access article distributed under the terms and conditions of the Creative Commons Attribution license (http://creativecommons.org/licenses/by/3.0/). 